\title{
The Irrational Behaviour of Individual Investors on Vietnam Stock Market: Prospect Theory-Based Approach
}

\author{
Hoang Thanh Hue Ton ${ }^{1,2} \&$ Ha Thuong Do ${ }^{2}$ \\ ${ }^{1}$ School of Management, Shanghai University, Shanghai 200444, China \\ ${ }^{2}$ School of Economics and Business Management, Hong Duc University, Thanh Hoa City, Viet Nam \\ Correspondence: Hoang Thanh Hue Ton, School of Management, Shanghai University, Shanghai 200444, China. \\ Tel: 86-159-2137-3032. E-mail: ththue14@gmail.com
}

\author{
Received: September 5, $2014 \quad$ Accepted: October 10, $2014 \quad$ Online Published: November 26, 2014 \\ doi: $10.5539 /$ jms.v4n4p47 \\ URL: http://dx.doi.org/10.5539/jms.v4n4p47
}

\begin{abstract}
The study aims to test whether the impact of the investors' psychological factors on their investment decisions conforms to the prospect theory or not. The used methodologyin is to interview by setting up assumption with different probability but the same expectation mean result. The survey of 422 investors on Vietnam Stock Market shows that the inconsistent psychology (irrational) exists commonly in the market. The investors show the risk-seeking tendency in risky situation and risk-aversion psychology in safe circumstances. The study reconfirms that the investors in Vietnam Stock Market are irrational investors.
\end{abstract}

Keywords: The prospect theory, irrational investors, the stock market, risk

\section{Introduction}

According to the normative theory, people should take the action in some way. In contrast, according to the positive theory, people set up models from what they have done. The expected utility theory is the normative theory which guides that economic activities shold be based inflexibly on headings. Although we have demonstrated the usefulness of this theory in describing people's behavior, but a lot of people ask the question, in the practical, how well this theory can describe behavior? Almost financial models mainly assume that investors assess investing risks as well as opportulities based on the expected utility theory by JohnVon Neumann and Oskar Morgenstern (1944), which means that the individual investor trades rationally as "rational" economic people and the investors make selections to maximize the final value of final asset according to risky conditions.

However, empirical studies taken by behavior behavioral financial researchers, namely Simon (1959, 1978 and 1987) and Kahneman and Tversky (1979, 1981, 1982 and 1992) proved that assumptions in tradional financial theories in general and in prospect utility theory in particular contain empirical imperfection. The study shows that sometime people refine information in an irrational way. Some imperfection of the "expected utility" theory found out by behavioral financial researchers helps to explain many financial events which have not been dealt with by traditional theories. Typical researchers finding out the inperfection of the "expected utility" theory, Kahneman and Tversky (1979) has made a range of testing to illustrate that people do not follow the expected utility theory systematically as they select risky assets.

In the year 2002, Daniel Kahneman was awarded the Economic Nobel Prize for the behavioral fianacial research and to bring out the Prospect theory, which lays the strong foundation for the behavioral finance. The prospect theory was developed by Daniel Kahneman và Tversky (1979) and then was improved by Tversky and Daniel Kahneman (1992) to be the Cumulative Prospect Theory, which was considered as a perfect support for the Expected Utility Theory.

\section{Prospect Theory: A Brief Overview}

The prospect theory assume that people's decisions are not only based on rational expectation but also affected by behavioral factors such as feeling, experience, social psychology. Besides, the prospect theory proposes that the risky preference of investors is not only inconsistent (which was mentioned in the expected utility theory), but changeable according to time and the market situation. 


\section{The content of the prospect theory}

Studies taken by Kahnerman and Tversky (1979, 1981, 1982 and 1992) and Ackert and Deaves (2010) concluded that:

(1) The people's activity has three main characteristics unexplained by the expected utility theory, based on the nature of the expectation that people sometime avert risk and sometime seek risk . As a result, the "gain-loss" situation marks a limit point between risk aversion and risk seeking psychology. People evaluate the gain and loss in consideration wit a reference point and reference point normally to the current status. People are afraid of losing, because the loss has worse impact on their psychology than the gain. This situation is called "the loss aversion".

(2) The background of the prospect theory is the value function built up by Kahneman and Tversky in 1979 to describe the utility level of financial investors through a concave utility function.

The asymmetric value function in the prospect theory replaces the utility function in the expected utility theory and is defined by the gain and loss according to the specific reference point. Ackert and Deaves (2010) argued that the utility level is measured by the income level, the value is defined by the gain and loss in comparison with the reference point. The value function contains following characteristics:

- The value function is concave in the gain area (risk aversion) and is convex in the loss area (risk seeking).

- The value function does not contain the income level, otherwise the income level change.

- The value further slopes forward the loss side (to reflect the loss-aversion psychology) than the gain area.

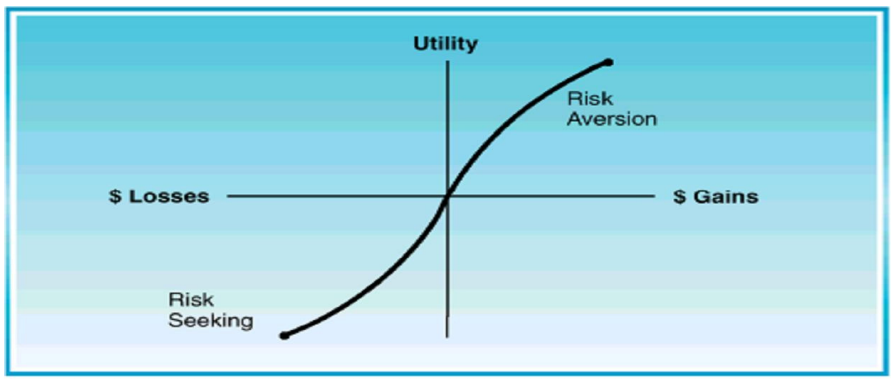

Figure 1. The typical value function description

According to the prospect theory, the value function is concave in the gain side and convex in the loss side and contains a spiral point at the co-ordinate, which is called the reference point. The reference point is considered by each individual as a comparison point in order to measure the aim level of the asset value. The value function has a larger slope with value levels under the reference point (the investor is losing), at this point the investor tends to seek risks, which means he/she is willing to accept the risk to continue to play the game with the hope of regaining the investment money and move towards above the reference point. In contrast, as the asset value point is above the reference point, the value function tends to be concave to describe the resistance behavior, the investor quicky sell out the stock to gain profit to avoid the risk without considering to increase the investment amount to enlarge the opportunity of making much more profit. Kahneman and Tversky conclude that investors prefer to take risk for losing investment while hesitate for taking risk for gaining investment. Finally, although the investors do not prefer taking risk for the gaining investment and tend to take risk in losing investment, and the loss impact more heavily on the investors than the gain does. This is due to the fact that the value function at the loss area is more slopping than the gain area, which means that the loss impacts more heavily on the investors' psychology than the gain does with the same absolute value. In another word, the investors will always behave in the risk aversion way.

(3) The expected utility theory can not help to explain why an investor makes an insurance policy while buying the lottery ticket, because buying the lottery ticket is considered as risk-seeking behavior. For lottery ticket buyers, the expectation value gained from the lottery ticket is much smaller than its price and the gaining opportunity is significant low for the buyers. However, this buyer can make an insurance policy to reduce the risk, which shows the risk aversion. The prospect theory can help to explain the reason for some people who at once buy the lottery ticket and make the insurance policy by setting up a higer rate for the gaining with the low probability. 


\section{The Researching Methodology}

In order to assess the attitude towards the risk of individual investors on Vietnam Stock Market, the questionare interviewing method is carried out. Chosen situations are designed based on Kahneman and Tversky $(1972,1973$, 1979, 1992, 2000); Ackert and Deaves (2010) to evaluate the attitude towards the risk of individual investors on the market and to investigate whether the investors on Vietnam Stock Market is rational and abide by the prospect theory or not? Finally, we designed six different situations for selections of taking the risk to take the opportunity to gain profit through the assumed investment decision for the investors on the market.

The investors were interviewed in September and Octorber 2013 on Hanoi and Ho Chi Minh Stock Exchange. The method to take samples based on the relation system with the estimated sample size of 400 samples. Firstly, the author set up a list of individual investors upon the connected relationship and then invited them to take part into a researching project. After that the project participants will go on to introduce potential candidates (other investors) to answer the available questionare. The selected interviewees are the investors of at least 6 months of experience on the market and at the interviewing time they still trade on the market. In order to conform to the ethic principal, the author pledge not to require the interviewees to write down their name. Especially, during the selection process, the main information are based on the following criterias: (1) the youngest are 18 years old and the oldest are 60 years old; (2) gender: male and female; (3) career: finance-banking, state agencies (ministries, departments, divisions and sectors), security companies, scientific and technological sectors; (4) qualification: the interviewees have different education levels of from the high school to the post graduated level.

\section{Result}

\section{Evidence of the existence of risk-aversion and risk-seeking psychology}

Table 1. Assess optimistic level in stock investment

\begin{tabular}{|c|c|c|c|c|}
\hline & & Count & $\begin{array}{l}\text { Column } \\
\text { N\% }\end{array}$ & $\begin{array}{c}\text { Cumulative } \\
\%\end{array}$ \\
\hline \multirow{5}{*}{$\begin{array}{l}\text { Decision 1.1: Imagine that you are } \\
\text { facing two abreast projects for } \\
\text { making decision. } \\
\text { Decision 1.2: Imagine that you are } \\
\text { facing two abreast projects for } \\
\text { making decision. }\end{array}$} & Project 1: definetely (100\%) gaining 250,000VND & 283 & $67 \%$ & $67 \%$ \\
\hline & $\begin{array}{l}\text { Project 2: the probability of } 25 \% \text { gaining a money amount of } \\
1,000,000 \mathrm{VND}\end{array}$ & 139 & $33 \%$ & $100 \%$ \\
\hline & Project 3: definetely $(100 \%)$ losing $750,000 \mathrm{VND}$ & 139 & $33 \%$ & $33 \%$ \\
\hline & Project 4 : the probability of $75 \%$ losing $1,000,000 \mathrm{VND}$ & 283 & $67 \%$ & $100 \%$ \\
\hline & Total & 422 & $100 \%$ & \\
\hline \multirow{5}{*}{$\begin{array}{l}\text { Decision 2.1: Imagine that you are } \\
\text { facing two abreast projects for } \\
\text { making decision. } \\
\text { Decision } 2.2 \text { : Imagine that you are } \\
\text { facing two abreast projects for } \\
\text { making decision. }\end{array}$} & Project 5: Selling out the stock and suffering the loss of $10,000 \mathrm{VND}$ & 249 & $41 \%$ & $41 \%$ \\
\hline & Project 6: Keeping the stock until the next month. & 173 & $59 \%$ & $100 \%$ \\
\hline & Project 7: Selling out the stock and taking the gain of $10,000 \mathrm{VND}$ & 241 & $57 \%$ & $57 \%$ \\
\hline & Project 8: Keeping the stock until the next month. & 181 & $43 \%$ & $100 \%$ \\
\hline & Total & 422 & $100 \%$ & \\
\hline \multirow{5}{*}{$\begin{array}{l}\text { Decision 3.1: Assume that you } \\
\text { will have } 3,000,000 \mathrm{VND} \text { in the } \\
\text { future. Select the suitable project. } \\
\text { Decision 3.2: Assume that you } \\
\text { will have } 5,000,000 \mathrm{VND} \text { in the } \\
\text { future. Select the suitable project. }\end{array}$} & Project 9: definitely $100 \%$ gaining $1,000,000 \mathrm{VND}$ & 282 & $67 \%$ & $67 \%$ \\
\hline & Project 10: $50 \%$ of the probability to gain $2,000,000 \mathrm{VND}$ & 140 & $33 \%$ & $100 \%$ \\
\hline & Project 11: definitely $100 \%$ losing $1,000,000$ VND & 169 & $40 \%$ & $52 \%$ \\
\hline & Project $12: 50 \%$ of the probability to lose $2,000,000 \mathrm{VND}$ & 253 & $60 \%$ & $100 \%$ \\
\hline & Total & 422 & $100 \%$ & \\
\hline \multirow{5}{*}{$\begin{array}{l}\text { Decision } 4.1 \text { (buying the lottery } \\
\text { ticket): select the suitable project: } \\
\text { Decision } 4.2 \text { (making the } \\
\text { insurance policy): select the } \\
\text { suitable project: }\end{array}$} & Project $13: 0,1 \%$ of the probability to gain $5,000,000 \mathrm{VND}$ & 304 & $72 \%$ & $72 \%$ \\
\hline & Project 14 : definitely $100 \%$ of the probability to gain $5,000 \mathrm{VND}$ & 118 & $28 \%$ & $100 \%$ \\
\hline & Project $15: 0,1 \%$ of the probability to lose $5,000,000 \mathrm{VND}$ & 203 & $48 \%$ & $48 \%$ \\
\hline & Project 16 : definitely $100 \%$ of the probability to lose $5,000 \mathrm{VND}$ & 219 & $52 \%$ & $100 \%$ \\
\hline & Total & 422 & $100 \%$ & \\
\hline \multirow{5}{*}{$\begin{array}{l}\text { Decision 5.1: It is required to } \\
\text { make two selections. } \\
\text { Decision 5.1: It is required to } \\
\text { make two selections. }\end{array}$} & Project $17: 80 \%$ of the probability to gain $4,000,000 \mathrm{VND}$ & 165 & $39 \%$ & $39 \%$ \\
\hline & Project 18 : definitely $100 \%$ of the probability to gain $3,000,000 \mathrm{VND}$ & 257 & $61 \%$ & $100 \%$ \\
\hline & Project $19: 20 \%$ of the probability to gain $4,000,000 \mathrm{VND}$ & 262 & $62 \%$ & $62 \%$ \\
\hline & Project $20: 25 \%$ of the probability to gain $3,0000,00 \mathrm{VND}$ & 160 & $38 \%$ & $100 \%$ \\
\hline & Total & 422 & $100 \%$ & \\
\hline \multirow{5}{*}{$\begin{array}{l}\text { Decision 6.1: It is required to } \\
\text { make two selections. } \\
\text { Decision 6.2: It is required to } \\
\text { make two selections. }\end{array}$} & Project $21: 45 \%$ of the probability to gain $\$ 6,000$ & 122 & $29 \%$ & $29 \%$ \\
\hline & Project $22: 90 \%$ of the probability to gain $\$ 3,000$ & 300 & $71 \%$ & $100 \%$ \\
\hline & Project $23: 0,1 \%$ of the probability to gain $\$ 6,000$ & 270 & $64 \%$ & $64 \%$ \\
\hline & Project $24: 0,2 \%$ of the probability to gain $\$ 3,000$ & 152 & $36 \%$ & $100 \%$ \\
\hline & Total & 422 & $100 \%$ & \\
\hline
\end{tabular}


The evidence of the existence of risk-aversion and risk-seeking psychology of investors is illustrated in the following $1^{\text {st }}$ research situation:

\section{Situation 1: Imagine that you are facing two abreast projects need to making decision. Consider the decision} and indicate which options you decide:

Decisio 1.1: select one out of:

Project 1: Definetely (100\%) gaining 250,000VND

Project 2: The probability of $25 \%$ gaining a money amount of $1,000,000$ VND

Decision 1.2: select one out of:

Project 3: Definetely (100\%) losing 750,000VND

Project 4: The probability of $75 \%$ losing $1,000,000$ VND

In this situation, the author designed selecting projects with the same probability of gaining or losing. Assuming that the rational person will have the selecting probability of 50:50, because selecting among projects has the same expectation of gain and loss. The survey result of this study is as follows:

In the decision 1.1 , there is $67 \%$ of investors (equally 283 people) select the project 1 is definetely to have $250,000 \mathrm{VND}$ and only 139 investors $(33 \%)$ select the $2^{\text {nd }}$ project with the probability of $25 \%$ of gaining $1,000,000 \mathrm{VND}$. As a result, the investors tend to adverse risk in this situation, although the gaining expectation is the same.

In the decision 1.2 , there is $66 \%$ of investors (equally 281 people) select the project 4 with the probability of $75 \%$ of losing $1,000,000 \mathrm{VND}$ and only $34 \%$ of investors (equally 141 people) select the project of firmly losing $750,000 \mathrm{VND}$. As a result, the investors tend to seek risk in the gaining expectation condition, or in another word, the investors show a more tendency to seek risk upon the gaining expectation.

The survey proved that the risk-aversion and risk-seeking psychology exist simultaneously among individual investors on Vietnam Stock Market in different chosing situations with the same expectation probability of gain (or loss) in the investment projects.

\section{Situation 2: Imagine that you are facing two abreast projects for making decision}

Decision 2.1: Assume that you bought a stock with the price of 50,000 VND, however, today, the price of that stock is only 40,000VND. You are considering whether you should sell out that stock to suffer a loss of $10,000 \mathrm{VND}$ or continue to keep it until the next month, with the assumption that the next month will happen following situations:

- The probability of $50 \%$ of the stock price will reduce to $30,000 \mathrm{VND}$

- The probability of $50 \%$ of the stock price will increase to reach $50,000 \mathrm{VND}$

Assume that there is no transaction cost or tax, with the above information, what project will you choose out of following projects:

Project 5: Selling out the stock and suffering the loss of 10,000VND

Project 6: Keeping the stock until the next month.

Decision 2.2: Assume that you bought a stock with the price of 50,000 VND, however, today, the price of that stock is $60,000 \mathrm{VND}$ You are considering whether you should sell out that stock or continue to keep it until the next month, with the assumption that the next month will happen following situations:

- The probability of $50 \%$ of the stock price will reduce to $50,000 \mathrm{VND}$

- The probability of $50 \%$ of the stock price will increase to reach $70,000 \mathrm{VND}$

Assume that there is no transaction cost or tax, with the above information, what project will you choose out of following projects:

Project 7: Selling out the stock and taking the gain of 10,000VND

Project 8: Keeping the stock until the next month.

The interviewing results are as follows:

In the decision 2.1 , there is $41 \%$ of investors (equally 173 people) select the project of suffering the loss of $1,000,000 \mathrm{VND}$ at the current time and $59 \%$ of investors (equally 249 people) select the project of keeping the 
stock until the end of the month upon the everage expectation of the situation of gaining 40,000VND as the current time.

In the decision 2.2 , there is $57 \%$ of investors (equally 241 people) select the project to sell the stock out immediately at the current time to gain only the profit of $10,000 \mathrm{VND}$ and only $43 \%$ of investors (equally 181 people) decide to keep the stock until the end of the month with the same gaining expectation.

The situation illustrated that although the investors concerned in many situation, they may seek risk in other situations. This proves that the inconsistency of investors in their investment decision, or in another word, they are not rational.

\section{Situation 3: Select the suitable project belongs to each decision:}

Decision 3.1: Assume that you will have 3,000,000 VND in the future. Select the suitable project:

Project 9: definitely $100 \%$ gaining 1,000,000 VND

Project 10: $50 \%$ of the probability to gain $2,000,000 \mathrm{VND}$

Decision 3.2: Assume that you will have 5,000,000 VND in the future. Select the suitable project:

Project 11: definitely $100 \%$ losing 1,000,000 VND

Project $12: 50 \%$ of the probability to lose $2,000,000 \mathrm{VND}$

The situation 3 shows that decision 3.1 and 3.2 are the same in reality. In both cases, the investors select to gain definitely $4,000,000 \mathrm{VND}$ and $50 \%$ of the probability to gain $5,000,000 \mathrm{VND}$ and $50 \%$ of the probability to gain $3,000,000$ VND. Or:

$\mathrm{P} 9=(5000000,50 ; 3000000, .50)=\mathrm{P} 11$, and $\mathrm{P} 10=(4000000)=\mathrm{P} 12$

Naturally, decision 3.2 is made from decision 3.1 by adding 1,000,000 VND to the beginning increased benefit and deducted 1,000,000 VND from the result. The increased benefit is not calculated to compare the expectations because they are the same in both selections in each decision.

The survey results taking from Hanoi and Ho Chi Minh Stock Exchanges proved that there is $67 \%$ of investors choosed project 9 and $33 \%$ of investors selected project 10 in decision 3.1 ; while there is $40 \%$ of investors selected project 11 and $60 \%$ of investors decided project 12 in decision 3.2. As a result, the investors averse risk in decision 3.1, but seek risk in decision 3.2. This situation shows the difference of the attitude towards the gain and the loss due to the change in income, but not due to the impact of income level on the investors' selection.

\section{Situation 4:}

Decision 4.1 (buying the lottery ticket): select the suitable project:

Project 13: $0,1 \%$ of the probability to gain 5,000,000VND

Project 14: definitely $100 \%$ of the probability to gain $5,000 \mathrm{VND}$

Decision 4.2 (making the insurance policy): select the suitable project:

Project 15: 0,1\% of the probability to lose 5,000,000VND

Project 16 : definitely $100 \%$ of the probability to lose 5,000 VND

The investor's interviewing results:

In decision 4.1 , there is $72 \%$ of investors (equally 304 people) willing to accepted the project to gain $5,000,000$ VND with the probability of $0.1 \%$ and there is only $28 \%$ of investors (equally 118 people) accepted the project to definitely take back 5,000VND. This proved that the investors made different decisions on taking risk, in this situation, the investors tended to seek risk rather than averse risk.

In decision 4.4, there is $48 \%$ of investors (equally 203 people) approved the project to lose 5,000,000 VND with the probability of $0.1 \%$ while $52 \%$ of investors accepted to gain 5,000 VND. This illustrated that the investors tended to averse risk as facing the loss.

\section{Situation 5: It is required to make two selections.}

\section{Decision 5.1:}

Project 17: $80 \%$ of the probability to gain $4,000,000 \mathrm{VND}$

Project 18: definitely $100 \%$ of the probability to gain $3,000,000 \mathrm{VND}$

Decision 5.2: 
Project 19: $20 \%$ of the probability to gain 4,000,000VND

Project 20: $25 \%$ of the probability to gain 3,0000,00VND

The two above decisions are similar, however, the probability level in decision 5.2 is $25 \%$. This scenario help to assess the response of the investors to the probability change as making the investment decision. The survey result shows that:

In decision 5.1, there is $61 \%$ of investors (equally 257 people) chose the project to firmly gain $3,000,000 \mathrm{VND}$, while only $39 \%$ of investors (equally 165 people) selected the project to gain 4,000,000VND with the probability of $80 \%$. This illustrated that there is a tendency to averse risk among the investors.

In decision 5.2, there is $62 \%$ of investors (equally 262 people) chose the project to firmly gain $4,000,000 \mathrm{VND}$ with the probability of $20 \%$, while only $38 \%$ of investors (equally 160 people) selected the project to gain $3,000,000 \mathrm{VND}$ with the probability of $25 \%$. From these two decisions, it is clear that the investors tended to be more risky as the probability level reduced, but they expected to gain a higher result.

\section{Situation 6: You select the suitable situation of the following abreast decisions.}

Decision 6.1:

Project 21: $45 \%$ of the probability to gain $6,000,000 \mathrm{VND}$

Project 22: $90 \%$ of the probability to gain $3,000,000 \mathrm{VND}$

Decision 6.2:

Project 23: $0,1 \%$ of the probability to gain $6,000,000 \mathrm{VND}$

Project $24: 0,2 \%$ of the probability to gain $3,000,000 \mathrm{VND}$

The interviewing result from scenario 6 of Vietnamese investors proved that there is $71 \%$ of investors selected project 22 (aversing risk) while $71 \%$ of investors chose project 23 , the rest included risk neutrals belonging to 2 selecting pairs of (project 21, project 22) and (project 23, project 24) had the same expectation. Note that in decision 6.1, the winning probability is high enough $(0.9$ and 0.45$)$ and most of investors chose the scenario with high winning probability.

\section{Conclusion}

The study illustrated that inconsistent psychology existed commonly among Vietnamese investors. In another word, the investors were irrational, they both aversed risk and sought risk in different scenarios. This result is corresponding to behavioral financial theory, especially the prospect theory. Generally, the investors tended to averse risk in the situation with high winning probability and to seek risk in the situation with low winning probability. This result is also according to Ackert \& Deaveas (2010), which proved that people tend to averse risk in the winning opportunities and to seek risk in losing opportunites. In another word, the "gain-loss" probability marks the turning-point between the investors' risk aversion and risk seeking.

The study also showed the irrationality in the investors' decisions on the market. The investors responded differently to the market changes. They had a contradictable tendency with the same gaining or losing expectation. The study also proved that the investors tend to expect for increasing the stock price and keep the stock as the real stock price decreases on the market and suffered the loss in their transaction, while they tend to sell the stock out as the real stock price increases to gain the profit. This shows the irrationality in their investment decisions, although the probabilities for future scenarios are the same, the investors tend to keep the stock when suffering the loss and sell the stock out when gaining the profit. This result is also suitable with our previous studies, which concluded that the current investors have the short-term investment strategies.

The study also shows that there is difference in the attitude towards risk due to the income change, but not the income level which impacts on the investors' selection. This is proved by Ackert \& Deaves (2010), which defines that people assess an opportunity based on the gain and loss in comparision with the reference income level. The reference income level of 4,000,000 VND was designed in this study. The investors tend to consider the loss more heavily than the gain with the same expectation value. In another word, people often feel more pessimistic as facing to the loss and more optimistic as taking the opportunity to avoid the loss or gain the profit with the same average result from their decisions.

The study proved that there is a contradictable psychology existing in the investors in buying the lottery ticket (gambling psychology) and making the insurance policy (provision psychology). However, the provision psychology is not popular among investors as they make decisions. The research illustrated that there is $52 \%$ of investors chose this situation, which is not clear enough to differ them, while the investors having the gambling 
psychology takes a large rate ( $72 \%$ of investors). This once again shows the psychology of seeking risk in risky opportunities and aversing risk in profitable opportunities. This result is also suitable with Kahneman and Tversky (1992), which prove that investors tend to seek risk at the positive value area, but when there is a little probability of gaining they will change to seek risk (explaining for buying the lottery ticket). In contrast, although the investors are seeking risk in the negative result area, they will change to avoid risk in case of the low probability of losing appears (explaining for making the insurance policy). This result proved that investors often averse risk for the gaining opportunities and seek risk for loosing opportunities as the probability for this result is high, but seek risk for the gaining opportunities and averse risk for loosing opportunities as the probability for this result is low. This is reasonable in Kahnerman and Tversky (1992), which shows that there is $92 \%$ (22 above 25 ) of fields containing the above characteristics. The prospect theory illistrates fully 4 aspects of the attitude towards risk by using a weighted function.

The study witnessed the "definite effect" existing among Vietnamese investors as facing to make risky and safe decisions. At the same level of expecting to gain the average income, the investors tend to choose the safe project and they are risk aversion investors at that time. However, when the safe probability is changed into the less-safe probability, the investors tend to choose the risky project accompanying to the expectation of higher income gain. This recomfirmed the "safe effect" discovered by Kahnerman and Tversky (1979) exists among the investors on Vietnam Stock Market. Kahnerman and Tversky (1979) argued that people assess the safe opportunities differently from the less-safe opportunities, because they often evaluate the safe opportunities more highly than the less-safe opportunities.

Besides, the study also refered to the projects with low gaining probability, the investors do not pay much attention to the gaining probability (although the probability of $1 \%$ is very different from the probability of $2 \%$ ), they only care much more the project with higher profit. This illustrates that the investors tend to seek risk in the risky situations and then pay much more attention to the gain value with a little probability.

The study shows that the attitude towards taking risk of the investors on Vietnam Stock Market is not explained by the expected utility maximazation theory. In another word, there is no evidence to illustrate that the investors are rational. The risk-aversion and risk-seeking psychology always exists in all investment decision required different selections. The attitude towards taking risk is different based on the calculation of the gain and loss trade-off upon considering the reference point.

The individual investors on Vietnam Stock Market are irrational. Therefore, the prospect theory of behavioral finance instead of the rational prospect theory is used to explain their bahaviors. As a result, the policies on developing Vietnam Stock Market are necessary to apply the theories of the behavioral finance. Based on the propect theory, the author interviewed deeply the individual investors on Vietnam Stock Market, which proved that they are irrational investors accroding to the prospect theory.

\section{Acknowledgments}

This work was supported in part by grants from the Innovation Program of Shanghai Municipal Education Commission (No. 13ZS065), the Shanghai Philosophy and Social Science Planning Project (No. 2012BGL006), and the National Social Science Foundation of China (No. 13CGL057).

\section{References}

Ackert \& Deaves. (2010). Behavioral Finance: Psychology, Decision-Making and Markets.

Kahneman, D., \& Tversky, A. (1979). Prospect theory: An analysis of decision under risk. Econometrica, 47(2), 263-291. http://dx.doi.org/10.2307/1914185

Simon, H. (1982). Models of bounded rationality: Behavioral economics and business organization. Cambridge, MA: MIT Press.

Simon, H. A. (1957). A behavioral model of rational choice. In H. A. Simon (Ed.), Models of man: Social and rational (pp. 24-60). New York: JohnWiley \& Sons, Inc.

Simon, H., \& Newell, A. (1982). Heuristic problem solving: The next advance in operations research. In Models of bounded rationality, Economic analysis (Vol. 1, pp. 380-389). Cambridge, MA: MIT Press.

Thaler, R. H. (2005). Advances in Behavioral Finance (Volume II). Princeton University Press.

Tversky, A., \& Kahneman, D. (1981). The framing of decisions and the psychology of choice. Science, (211), 453-458. http://dx.doi.org/10.1126/science.7455683

Tversky, A., \& Kahneman, D. (1982). Judgments of and by representativeness. In D. Kahneman, P. Slovic, \& A. 
Tversky (Eds.), Judgment under uncertainty: Heuristics and Biases. Cambridge, U.K.: Cambridge University Press. http://dx.doi.org/10.1017/CBO9780511809477.007

Tversky, A., \& Kahneman, D. (1992). Advances in prospect theory: Cumulative representation of uncertainty. Journal of Risk and Uncertainty, (5), 297-323. http://dx.doi.org/10.1007/BF00122574

Von Neumann, J., \& Morgenstern, O. (1944). Theory of Games and Economic Behavior. Princeton, New Jersey: Princeton University Press.

Von Neumann, J., \& Morgenstern, O. (1944). Theory of Games and Economic Behavior. Princeton: Princeton University Press.

\section{Copyrights}

Copyright for this article is retained by the author(s), with first publication rights granted to the journal.

This is an open-access article distributed under the terms and conditions of the Creative Commons Attribution license (http://creativecommons.org/licenses/by/3.0/). 